\section{Non-Radioisotopic AFLP Method Using PCR Primers Fluorescently Labeled with $\mathrm{Cy}^{\mathrm{TM} 5}$}

BioTechniques 26:236-238 (February 1999)

Amplified fragment-length polymorphism (AFLP) is a polymerase chain reaction (PCR)-based technique that allows large numbers of polymorphic loci closely linked to a genetic locus of interest to be uncovered in the absence of a detailed preexisting genetic map. In existing protocols, AFLP products are separated by denaturing polyacrylamide gel electrophoresis (PAGE) and detected either radioisotopically (4) or by silver staining (1). We have developed a non-radioisotopic modification of the AFLP method that uses $5^{\prime} \mathrm{Cy}^{\mathrm{TM}} 5$ end-labeled oligonucleotides (Table 1). Cy5 is a fluorescent molecule with absorption and emission maxima at 649 and $670 \mathrm{~nm}$, respectively. It can be covalently attached to the $5^{\prime}$ end of oligonucleotides during synthesis (3). Cy5-modified oligonucleotides are available through many suppliers of custom synthesized oligonucleotides; we obtained ours from Genosys Biotechnologies (The Woodlands, TX, USA). Although they are more expensive to synthesize than unlabeled oligonucleotides, the modification is stable for years, and a small amount of oligonucleotide can be used for many rounds of AFLP, giving this method a low cost per reaction. Cy5 is neither radioactive nor biohazardous, so safety and waste disposal are not concerns. Cy5-labeled AFLP products are detected by scanning wet or dried sequencing gels using a fluorescence imager, eliminating the need for X-ray film. A fullsized gel can be scanned in approximately $11 \mathrm{~min}$ on a Storm ${ }^{\mathrm{TM}} 850$ PhosphorImager ${ }^{\mathrm{TM}}$ (Molecular Dynamics, Sunnyvale, CA, USA).

We tested the effectiveness of Cy5 AFLP by performing bulked segregant analysis (2) to compare two pools of genomic DNA from phenotypically mutant and phenotypically wild-type (WT) F2 progeny from a zebrafish mutant mapping cross. Table 1 details the protocol we used.

Genomic DNA pools were each made up of DNA from 20-30, 5-dayold F2 embryos. A total of 24 different preamplification PCRs were performed [2 genomic DNA pools (WT and mutant) $\times 3$ different EcoRI-N primers $\times 4$ different $M s e I-N$ primers]. AFLP reactions were set up using Cy5-EcoRINNN and $M s e$ I-NNN primers that had the same first variable $3^{\prime}$ base $(-\mathrm{N})$ as the primers used to generate the preamplification reaction, which was used as the PCR template. Each preamplifica- tion reaction template was thus used for a total of 256 different AFLP reactions (for example, 16 different Cy5-EcoRIGNN primers $\times 16$ different $M s e I-G N N$ primers $=256$ PCRs), and the full AFLP set was composed of 6144 PCRs (24 preamplification templates $\times 256$ PCRs).

We found that the sensitivity of the Cy5 method was comparable to that of radioisotopic methods, PCR amplification was robust and the pattern of products was highly reproducible. When corresponding AFLP reactions from

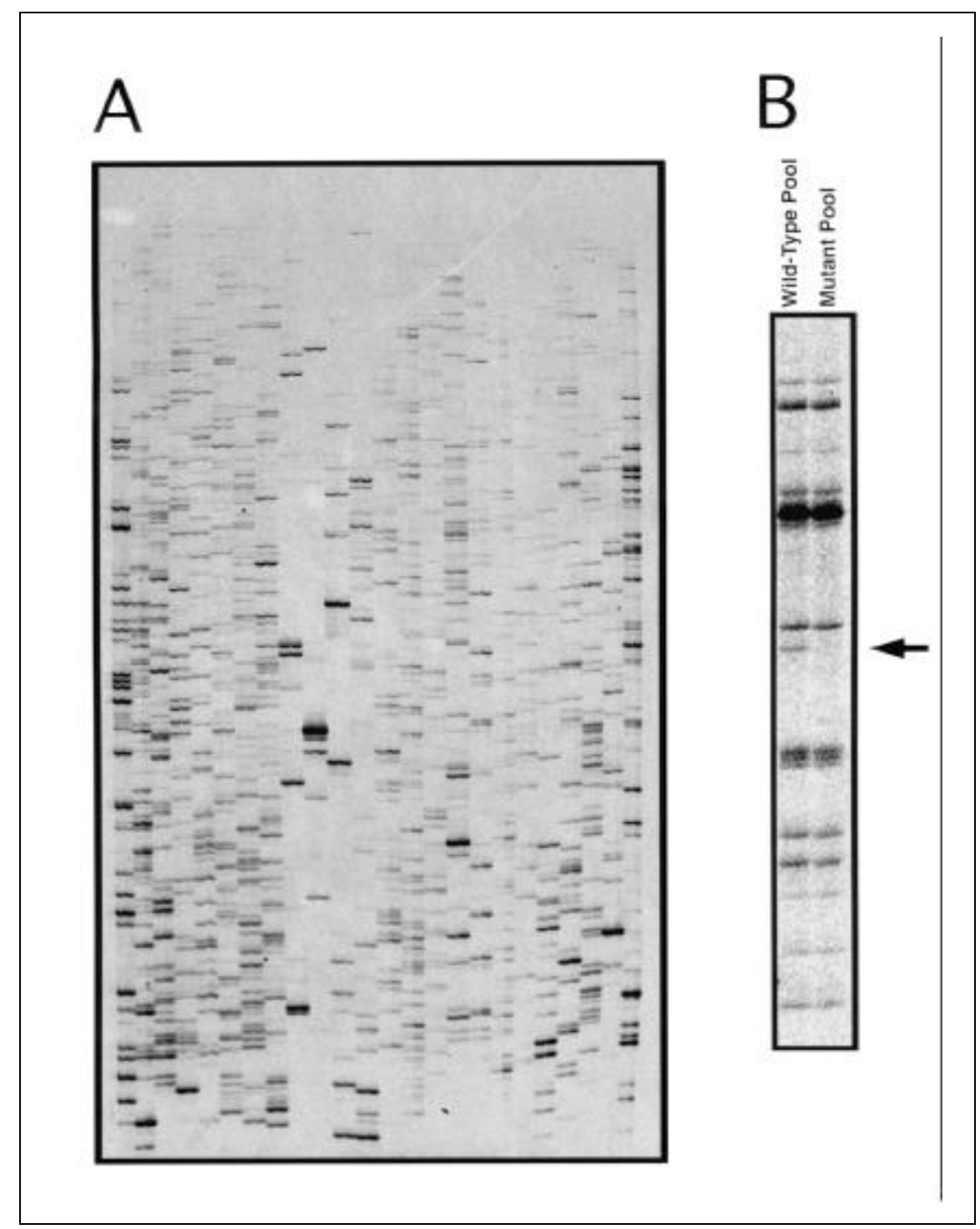

Figure 1. Results of AFLP-PCR using Cy5-end labeling and fluorescence scanning detection of electrophoresed PCR products. (A) Typical fluorescence scan of an AFLP sequencing gel, containing 24 pairs of mutant/WT AFLP-PCR products. In general, the patterns present in the mutant and WT lanes are identical. (B) Higher magnification view of a pair of AFLP-PCR lanes showing a polymorphic amplified fragment, which is present in the WT pool lane but absent or greatly reduced in the mutant pool lane (arrow). This is a candidate for a polymorphic marker linked to the mutation. 
1. Digest Genomic DNA. Digest approximately $400 \mathrm{ng}$ purified F2 pool genomic DNA with $6.25 \mathrm{U} \mathrm{EcoRI}$ and $6.25 \mathrm{U}$ Msel in a $50-\mu \mathrm{L}$ reaction. Digest at $37^{\circ} \mathrm{C}$ for $3 \mathrm{~h}$. Heat-inactivate at $60^{\circ} \mathrm{C}$ for $20 \mathrm{~min}$.

2. Ligate on AFLP adapters. Add 1.25 $\mu \mathrm{L}$ Buffer 2, $0.125 \mu \mathrm{L} 100 \times$ bovine serum albumin (BSA) (both from New England Biolabs, Beverly, MA, USA), $0.625 \mu \mathrm{L} 100 \mathrm{mM}$ ATP, $0.65 \mu \mathrm{L} 10-\mu \mathrm{M}$ EcoRI adapter and $0.65 \mu \mathrm{L} \mathrm{10- \mu \textrm {M }}$ Msel adapter, $3.0375 \mu \mathrm{L}$ double-distilled $(\mathrm{dd}) \mathrm{H}_{2} \mathrm{O}, 125 \mathrm{U}$ ligase (New England Biolabs) and $\mathrm{dd}_{2} \mathrm{O}$ to $62.5 \mu \mathrm{L}$. Incubate at $37^{\circ} \mathrm{C}$ for $3 \mathrm{~h}$. Adapters are prepared by separately annealing together $E c o R I$ adapter oligonucleotides (5'-CTCGTAGACTGCGTACC-3' and 5'-AATTGGTACGCAGTCTAC-3') and Msel adapter oligonucleotides (5'-GACGATGAGTCCTGAG-3' and 5'TACTCAGGACTCAT-3').

3. First-round (preamplification) PCR. Dilute ligation reactions 1:10 in $\mathrm{dd} \mathrm{H}_{2} \mathrm{O}$. To $5 \mu \mathrm{L}$ diluted ligation, add $30 \mathrm{ng}$ each EcoRI-N primer (5'-GACTGCGTACCAATTCN-3') and Msel-N primer (5'-GATGAGTCCTGAGTAAN-3'), $2 \mu \mathrm{L} 10 \times$ thermophilic buffer (Promega, Madison. WI, USA), $1.2 \mu \mathrm{L} 25 \mathrm{mM}$ $\mathrm{MgCl}_{2}$ (Promega), $0.2 \mu \mathrm{L} 20 \mathrm{mM}$ dNTPs (Amersham Pharmacia Biotech, Piscataway, NJ, USA), $0.1 \mu \mathrm{L}$ Taq DNA Polymerase (Promega) and $\mathrm{dd}_{2} \mathrm{O}$ to $20 \mu \mathrm{L}$. Perform 20 cycles of PCR amplification at $94^{\circ} \mathrm{C}$ for $30 \mathrm{~s}, 56^{\circ} \mathrm{C}$ for $30 \mathrm{~s}$ and $72^{\circ} \mathrm{C}$ for $60 \mathrm{~s}$.

4. Second-round (AFLP) PCR. Dilute preamplification reactions 1:100 in $\mathrm{ddH}_{2} \mathrm{O}$. To $5 \mu \mathrm{L}$ diluted preamplification reaction, add $25 \mathrm{ng}$ Cy5-EcoRI-NNN primer (5'-Cy5-GACTGCGTACCAATTCNNN-3'), 150 ng Msel-NNN primer (5'-GATGAGTCCTGAGTAANNN-3'), $2 \mu \mathrm{L}$ 10x thermophilic buffer, $1.2 \mu \mathrm{L} 25$ $\mathrm{mM} \mathrm{MgCl}_{2}, 0.2 \mu \mathrm{L} 20 \mathrm{mM}$ dNTPs, $0.1 \mu \mathrm{L}$ Taq DNA polymerase and $\mathrm{ddH}_{2} \mathrm{O}$ to $20 \mu \mathrm{L}$. Perform 13 cycles of PCR amplification at $94^{\circ} \mathrm{C}$ for $30 \mathrm{~s}, 65^{\circ} \mathrm{C}$ for $30 \mathrm{~s}$ and $72^{\circ} \mathrm{C}$ for $60 \mathrm{~s}$, lowering the annealing temperature by $0.7^{\circ} \mathrm{C}$ each cycle. Then perform 24 cycles of PCR amplification at $94^{\circ} \mathrm{C}$ for $30 \mathrm{~s}, 56^{\circ} \mathrm{C}$ for $30 \mathrm{~s}$ and $72^{\circ} \mathrm{C}$ for $60 \mathrm{~s}$.

5. Sample preparation. Add $20 \mu \mathrm{L}$ loading buffer (formamide plus dash bromphenol blue) to each reaction, and store samples at least $24 \mathrm{~h}$ at $-20^{\circ} \mathrm{C}$.

6. Gel electrophoresis and fluorescence scanning. Run samples out on standard $6 \%$ polyacrylamide sequencing gels (pre-run for $15 \mathrm{~min}$ ). Scan wet gels (for maximum time efficiency) or dried gels (for greatest signal strength) on a Storm 850 Phosphorlmager using the red fluorescence channel. Reference marks made using a standard black ink marker on $3 \mathrm{MM}$ paper backing the gel are visible after scanning as "negative" images over a low background.

mutant and WT bulked segregant pools were run out in adjacent lanes of a polyacrylamide gel, virtually every band in the paired lanes was equivalent (Figure 1A). Ninety-two percent of primer pairs gave completely identical patterns of fragments in both AFLP samples. This made it easy to identify candidate linked polymorphic marker loci, which were detected as bands present in a WT lane but absent from the corresponding mutant lane (Figure 1B). Actual linkage of these potential markers to the mutant locus was assessed by performing additional preamplification and AFLP reactions, using the same primer pair, on DNA from individual mutant and WT map cross progeny. Ninety percent of candidate markers were linked to the mutation, while most of the remaining $10 \%$ were simply difficult to score and not conclusively shown to be unlinked. In conclusion, our Cy5 AFLP method is highly reproducible and gives rise to 
few false positives, making it a safe, cost-effective alternative to radioisotopic AFLP methods.

\section{REFERENCES}

\footnotetext{
1.Falcone, E., P. Spadafora, M. De Luca, R. Ruffolo, C. Brancati and G. De Benedictis. 1995. DYS19, D12S67, and D1S80 polymorphisms in population samples from southern Italy and Greece. Hum. Biol. 67:689-701.

2.Michelmore, R.W., I. Paran and R.V. Kesseli. 1991. Identification of markers linked to disease-resistance genes by bulked segregant analysis: a rapid method to detect markers in specific genomic regions by using segregating populations. Proc. Natl. Acad. Sci. USA 88:9828-9832.

3.Mujumdar, S.R., R.B. Mujumdar, C.M. Grant and A.S. Waggoner. 1996. Cyaninelabeling reagents: sulfobenzindocyanine succinimidyl esters. Bioconjug. Chem. 7:356362.

4.Vos, P., R. Hogers, M. Bleeker, M. Reijans, T. van de Lee, M. Hornes, A. Frijters, J. Pot et al. 1995. AFLP: a new technique for DNA fingerprinting. Nucleic Acids Res. 23:44074414.
}

Address correspondence to Dr. Brant M. Weinstein, Laboratory of Molecular Genetics, NICHD, National Institutes of Health, Building 6B, Room 309, 6 Center Drive, Bethesda, MD 20892, USA. Internet: bw96w@nih.gov

Received 17 August 1998; accepted 19 October 1998.

Beth L. Roman, Van N. Pham, Paul E. Bennett and Brant M. Weinstein

National Institute of Child Health and Human

Development

NIH, Bethesda, MD, USA

\section{PCR Alone is Insufficient for Identifying Structural Modifications to Yeast Chromosomes}

BioTechniques 26:238-240 (February 1999)

The yeast Saccharomyces cerevisiae is a widely used eukaryote model with a variety of attributes that facilitate molecular genetic analysis of gene structure and function (2). Among the powerful technologies applicable to yeast are several systems for introducing new genetic material into cells, either as freely replicating linear or circular mini-chromosomes $(3,4)$ or by direct modification of yeast chromosomal loci by gene targeting $(12,15,17)$. The propensity of yeast to carry out homologous recombination greatly simplifies gene-targeting procedures, and many types of chromosomal changes can be made, including gross changes such as total or partial gene deletions, duplications, triplications, etc. and subtle changes such as defined point mutations. Although gene targeting in yeast is relatively efficient, a significant fraction of transformants are often found to carry undesired chromosomal changes, and therefore it is necessary to screen several candidates to identify one with the desired modification. Some undesired changes might result, for example, from nonhomologous recombination $(18,19)$.

Modifications to yeast chromosomes can be confirmed by using Southern hybridization, which provides a view of all parts of a genome homologous to the probe and therefore is well-suited for characterizing changes to chromosomal loci. However, Southern hybridization is time-consuming, and the required sensitivity is obtained only with radioactive probes or relatively expensive nonradioactive detection methods. In contrast, polymerase chain reaction (PCR) is simple, fast and inexpensive, and its great sensitivity does not require radioactive probes or complex detection

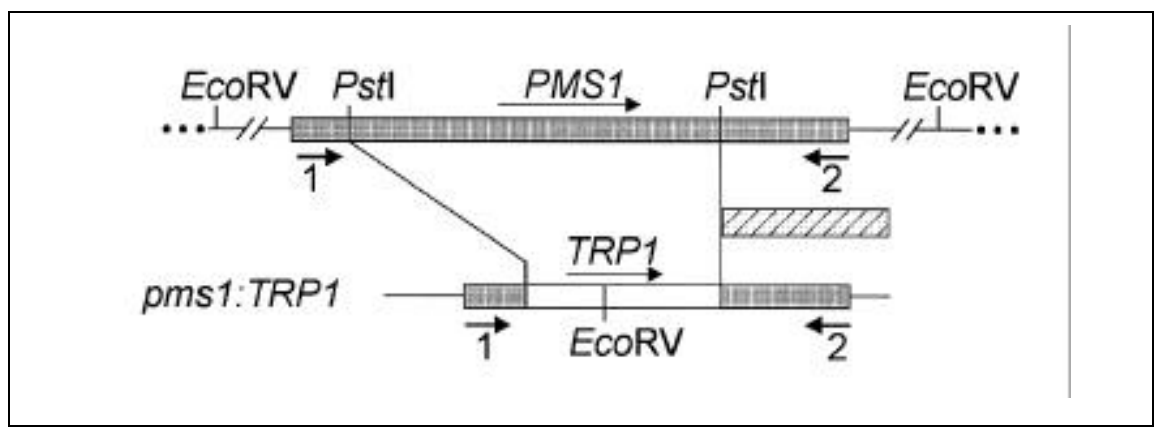

Figure 1. Structures of PMS1 and pms 1:TRP1 alleles. A 2.0-kbp PstI fragment containing most of the $P M S 1$ coding sequence (top) was replaced by a $0.8-\mathrm{kbp} T R P 1$ fragment, creating the insert present in pEA193. Digestion of pEA193 with SalI releases the 2.8-kbp insert with 1.1 and $0.9 \mathrm{kbp}$ of up- and downstream pms 1 sequences flanking TRP 1 (bottom). PCR primers (labeled arrows 1 and 2) amplify the 2.1- and 1.0-kbp fragments from PMS1 and pms 1:TRP1 alleles, respectively. A hybridization probe derived from pEA193 is shown by the hatched box.

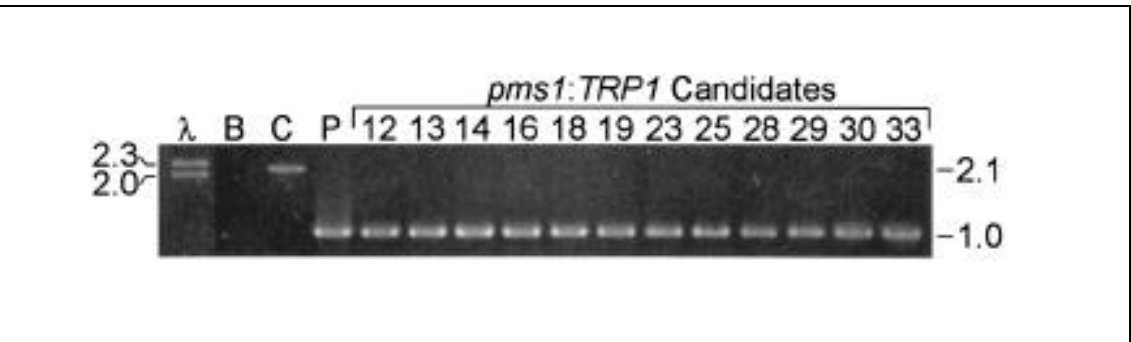

Figure 2. PCR amplification of PMS1 and pms1:TRP1 candidates. Standard PCRs contained approximately $0.5 \mu \mathrm{g}$ of yeast genomic DNA, $0.01 \mu \mathrm{g}$ of pEA193 (lane P) or no DNA (lane B). Lane C indicates the WT PMS1 control (JW3082). Reactions were run for 35 cycles $\left(94^{\circ} \mathrm{C}\right.$ for $1 \mathrm{~min}, 50^{\circ} \mathrm{C}$ for $1 \mathrm{~min}$ and $72^{\circ} \mathrm{C}$ for $2 \mathrm{~min}$ ). Lane $\lambda$ indicates $\lambda /$ HindIII size markers; sizes given in kbp. 